\title{
Selection of the Proper Hammer in Pile Driving and Estimation of the Total Driving Time
}

\author{
Alireza Afshani ${ }^{1}$, Ali Fakher ${ }^{2}$ and Massoud Palassi ${ }^{2}$ \\ 1. Faculty of Science and Engineering, Waseda University, Tokyo 169-8555, Japan \\ 2. Department of Civil Engineering, University of Tehran, Tehran 11365-4563, Iran
}

\begin{abstract}
There are various methods for analyzing pile driving process such as dynamic formulas, wave equation analyses and dynamic measurements. The programs of the two latter methods are relatively expensive to purchase and also require trained engineers to interpret the data it collects. Meanwhile, the use of the site specific empirical formulas based on the real cases of pile driving and output analyses of the wave equation analysis programs can be beneficial. In the current study, pile driving data from three sites in the south of Iran were collected. Using the data of these cases and one-dimensional wave equation analysis program GRLWEAP, couple of experimental formulas which determine the proper range of hammer's ID for driving a pile, are proposed. Finally, due to the importance of the time in marine projects, another experimental formula is also proposed for estimation of the total driving time.
\end{abstract}

Key words: Pile driving, hammer selection, total driving time, GRLWEAP, driveability analysis.

\section{Introduction}

Engineers and contractors have been designing and installing pile foundations for many years. The most common way of installing a pile is driving of it by a hammer especially in marine environments. A hammer which is too small may not be able to drive the pile to the required capacity, or may need an excessive number of blows. On the other hand, a hammer which is too large may damage the pile or fails to operate properly after a few blows.

Three general methods are available for predicting the hammer performance: dynamic formulae, dynamic test and wave equation analysis. Dynamic test methods measure strain and acceleration of the produced wave by hammer impact near the pile head. These measurements can be used to evaluate the performance of the pile driving system, determine pile integrity and estimate static pile capacity. But these tests must be performed during pile driving and also need trained

Corresponding author: Alireza Afshani, Dr. student, research fields: civil engineering and geotechnical engineering. E-mail: aafshani@moegi.waseda.jp. engineers to interpret the data it collects. Wave equation analysis performed in the design stage requires assumptions on the hammer type and performance level, the drive system components, as well as the soil response during driving.

In the current paper, based on the field observation data and a parametric study, couples of experimental equations were presented to provide a proper hammer for driving a certain pile in a certain soil condition. Furthermore, an equation was also obtained which represents an estimation of the total driving time.

\section{Driveability Analysis}

\subsection{The Basics of Driveability Analysis}

By performing a static soil analysis the graph of ultimate soil capacity as function of depth can be plotted. The wave equation is then used to calculate the blow count for certain depth value. In this way, the blow count versus embedded length curve is obtained. This process is called a driveability study which can be performed: 
(1) To determine if the proposed hammer(s) are suitable for the pile installation;

(2) To assess the ability of the hammer(s) to restart pile driving after an interruption.

\subsection{GRLWEAP Program}

GRLWEAP is the latest updated wave equation analysis program [1]. This program simulates motions and forces in foundation pile when driven by either impact or vibratory hammer. The program can compute the following:

(1) The blow count of a pile under one or more assumed ultimate resistance values and other dynamic soil resistance parameters, given a hammer and a driving system (helmet, hammer cushion and pile cushion);

(2) The energy transferred by the hammer to the pile for each capacity analyzed;

(3) The expected blow count per meter along the penetrated depth of the pile (driveability analysis).

\section{Field Measurements of the Pile Driving}

\subsection{General Description}

During the process of obtaining an equation for selecting a proper hammer to drive a pile, a series of data was needed to calibrate the unknown parameters in the used wave equation program. In order to fulfill this goal, the field data from three recent pile installation projects were collected. All three projects were located in the south of Iran on the coastline of the Persian Gulf. More details of these projects are presented in subsequent parts.

\subsection{Site A}

This site has located on Bahonar harbor in Bandar-Abbas, a port city on the southern coast of Iran, on the Persian Gulf. At this site, abundant numbers of piles were driven as a deep foundation which their characteristics are: piles type = open-ended steel pipe pile, piles total length $=24$ to $36 \mathrm{~m}$, piles embedded length $=16$ to $30 \mathrm{~m}$, piles diameter $=0.762 \mathrm{~m}$, piles wall thickness $=18 \mathrm{~mm}$. The Delmag D-36 was chosen as a typical diesel hammer with an efficiency of 0.8 . The general soil profile was consisted of dense to hard silty sand as described in Table 1. In order to calibrate the input information of the GRLWEAP program for the next analyses, field data of blow counts per meter was collected in each of these projects. For instance, in site A, the blow counts per meter along the driven length of the 15 cases of pile driving were gathered which has been summarized in Table 2 .

\subsection{Site $B$}

This site was in Kish, a resort island in the Persian Gulf and was performed as an expansion phase of Kish commercial harbor. The characteristics of used piles are: piles type $=$ open-ended steel pipe pile, piles total length $=7 \mathrm{~m}$, piles embedded length $=6.75 \mathrm{~m}$, piles diameter $=0.914 \mathrm{~m}$, piles wall thickness $=16 \mathrm{~mm}$. The hammer which was used to drive the piles was Delmag D-62-22 with approximate efficiency of 0.85 . The soil condition of this site is summarized in Table 1. Based upon field observation, four records of blow counts per meter along the driven length of piles were gathered during the driving process. The total numbers of blow counts along the entire driven length of these piles have been shown in Table 2 .

Table 1 Soil condition in sites A, B, and C.

\begin{tabular}{lll}
\hline From $(\mathrm{m})$ & To $(\mathrm{m})$ & Description \\
\hline Site A & & \\
\hline 0 & 12 & Dense silty sand \\
12 & 18 & Very dense clayey silty sand \\
18 & 28 & Hard silty clay \\
28 & 43 & Very dense sandy silt \\
\hline Site B & & \\
\hline 0 & 7 & Back fill material \\
7 & 17 & Sandy soil with some shell debris \\
17 & 27 & Clayey soil with layers of dense silt \\
27 & - & Clayey soil with layers of V. dense silt \\
\hline Site C & & \\
\hline 0 & 12 & Gray silty sand \\
12 & 22 & Very dense silty gravel with sand \\
22 & 27 & Very dense silty gravel with sand and \\
27 & - & gobble \\
\hline
\end{tabular}


Table 2 Collected field records of sites A, B, and C.

\begin{tabular}{|c|c|c|c|c|}
\hline \multicolumn{5}{|l|}{ Site A } \\
\hline Pile No. & Total pile Length (m) & $\begin{array}{l}\text { Driven length of the pile } \\
(\mathrm{m})\end{array}$ & Hammer model & $\begin{array}{l}\text { Total number of the blow } \\
\text { (counts) }\end{array}$ \\
\hline A1 & 31.45 & 16.45 & $D^{a}-36$ & 970 \\
\hline B1 & 31 & 16 & D-36 & 848 \\
\hline $\mathrm{C} 1$ & 31 & 16 & D-36 & 896 \\
\hline B2 & 35.1 & 23.1 & D-36 & 1,632 \\
\hline $\mathrm{C} 2$ & 35 & 23 & D-36 & 1,570 \\
\hline B3 & 36.31 & 29.6 & D-36 & 2,925 \\
\hline A4 & 24.3 & 22.3 & D-36 & 1,521 \\
\hline B4 & 24.3 & 22.3 & D-36 & 1,367 \\
\hline M1-1 & 32 & 18 & D-36 & 1,808 \\
\hline M1-2 & 34.65 & 23.65 & D-36 & 2,115 \\
\hline M1-3 & 32 & 18 & D-36 & 2,405 \\
\hline M3-1 & 32 & 18 & D-36 & 2,009 \\
\hline M3-3 & 32 & 18 & D-36 & 1,856 \\
\hline M4-1 & 32 & 18 & D-36 & 1,837 \\
\hline M4-3 & 32 & 18 & D-36 & 1,817 \\
\hline \multicolumn{5}{|l|}{ Site B } \\
\hline Pile No. & Total pile length (m) & $\begin{array}{l}\text { Driven length of the pile } \\
(\mathrm{m})\end{array}$ & Hammer model & $\begin{array}{l}\text { Total number of the blow } \\
\text { (counts) }\end{array}$ \\
\hline L3-AP3 & 7 & 6.75 & D-62-22 & 80 \\
\hline L3-AP4 & 7 & 6.75 & D-62-22 & 117 \\
\hline L3-AP5 & 7 & 6.25 & D-62-22 & 31 \\
\hline L3-AP6 & 7 & 6.5 & D-62-22 & 41 \\
\hline \multicolumn{5}{|l|}{ Site C } \\
\hline Pile No. & Total pile length (m) & $\begin{array}{l}\text { Recorded length of the } \\
\text { pile }^{b}(\mathrm{~m})\end{array}$ & Hammer model & $\begin{array}{l}\text { Total number of the } \\
\text { blow(counts) }\end{array}$ \\
\hline B31 & 38.6 & 9.48 & D-100-13 & 1,134 \\
\hline A 32 & 38.6 & 5.52 & D-100-13 & 761 \\
\hline A27 & 38.6 & 7.34 & D-100-13 & 918 \\
\hline B32 & 38.6 & 8.54 & D-100-13 & 984 \\
\hline A34 & 38.6 & 8.6 & D-100-13 & 920 \\
\hline $\mathrm{C} 34$ & 38.6 & 8.33 & D-100-13 & 1,089 \\
\hline B35 & 38.6 & 7.79 & D-100-13 & 1,012 \\
\hline $\mathrm{C} 31$ & 38.6 & 7.2 & D-100-13 & 946 \\
\hline B37 & 24 & 9 & D-46 & 978 \\
\hline A 37 & 24 & 8.95 & D-100-13 & 1,293 \\
\hline E34 & 39.6 & 8.64 & D-100-13 & 843 \\
\hline D43 & 39.6 & 8.96 & D-100-13 & 1,160 \\
\hline D42 & 39.6 & 8.71 & D-100-13 & 958 \\
\hline B31 & 39.6 & 8.2 & D-100-13 & 1,016 \\
\hline
\end{tabular}

${ }^{\mathrm{a}} \mathrm{D}$ denotes Delmag diesel hammer.

${ }^{\mathrm{b}}$ The blow count per meter has been recorded in this length which shows the last few meter of the driven length. 


\subsection{Site C}

This site locates in Kangan harbor, a small harbor in Kangan town in the coastline of the Persian Gulf on Bushehr province. Multitude numbers of large diameter piles were driven by Delmag D-100-13 and Delmag D-46 with estimate efficiency of 0.85. Piles characteristics were: pile type $=$ open-ended steel pipe pile, pile total length $=$ maximum $40 \mathrm{~m}$, pile embedded length $=25$ to $30 \mathrm{~m}$, pile diameter $=1.422 \mathrm{~m}$, pile wall thickness $=19.8 \mathrm{~mm}$. The soil profile mainly consists of the normal to the very dense silty sand and gravel. The general soil profile is described in Table 1. Totally, fourteen records of blow counts per meter along the penetrated length of pile were gathered. But in this site, these records are only pertaining to the last few meter of driving length which has been shown in Table 2. The total number of blow counts along the recorded driven length of the piles has presented in the last column of Table 2 .

\section{Calibration of Ingoing Parameters in GRLWEAP from Field Test Data}

Calibration Procedure, The analyses have been carried out in this study using GRLWEAP program. The soil parameters needed for analyses are: toe quake - Qt, skin quake - Qs, which describe maximum elastic deformation at the toe and skin of the pile, toe damping - Jt, skin damping - Js, which describe dynamic behavior of the soil at the toe and skin of the pile respectively. The required driving system properties are hammer and pile cushions information such as cross sectional area, elastic modulus, thickness, coefficient of restitution, cushions' stiffness and helmet weight. Physical and mechanical properties of pile are also needed. All of the above information was provided from field data except soil properties and the hammer cushion's stiffness.

The unknown parameters were back-calculated from the blow counts per meter, which were directly collected in the field as presented in Table 2. To initiate the iterative process, starting estimates are required.
The typical values of smith damping and quake parameters recommended by others Ref. [1-3] are used to obtain starting estimates for $Q_{t}, Q_{s}, J_{s}$ and $J_{t}$. These values have been shown in Table 3 .

Stiffness of hammer cushion is calculated from $E A / t$, where $E$ is the elastic modulus, $A$ is the cross sectional area and $t$ is the thickness of the cushion. Used hammer cushion material in the both of sites $\mathrm{A}$ and $\mathrm{B}$ were a few rounds of stiff towing wire, while wood hammer cushion was used in site $\mathrm{C}$.

Values of hammer cushion stiffness after calibration were obtained during matching process of blow counts per meter in the field with GRLWEAP output at each site.

Table 3 shows the quantities of the unknown parameters in GRLWEAP before and after calibration. As it can be seen from Table 3, difference in values of stiffness after calibration is because of the fact that used material at each site is different. Using stiffness value of Table 3 after calibration, recorded data at each site were matched with GRLWEAP output.

In order to evaluate the calibration result, measured blow counts per meter of the field were compared with GRLWEAP program output after calibration process. For instance, the calibration result in the site $\mathrm{B}$ has been displayed in Fig. 1.

\section{Parametric Study}

After calibration of driveability analyses for each of three above mentioned sites, a parametric study was undertaken for each site to produce more data. This parametric study also considers the effects of various involving parameters on the numbers of the blow counts per meter $-\mathrm{n}$. These parameters are: (1) coefficient of restitution of the hammer cushion, COR (coefficient of restitution), which shows amount of energy dissipation when ram impacts a pile cushion; (2) toe quake $-Q_{t}$, which describes maximum elastic deformation of the soil at the pile toe; (3) skin damping - $J_{s}$, which describes dynamic behavior of soil at the skin of the pile; (4) helmet weight; (5) stiffness of the hammer cushion $-k ;(6)$ embedded length of the pile. 
Table 3 Values of unknown parameters in GRLWEPA before and after calibration in different sites.

\begin{tabular}{|c|c|c|c|c|c|}
\hline & Qs & Qt & Js & $\mathrm{Jt}$ & Hammer cushion stiffness \\
\hline Site name & $(\mathrm{mm})$ & $(\mathrm{mm})$ & $(\mathrm{sec} / \mathrm{m})$ & $(\mathrm{sec} / \mathrm{m})$ & $(\mathrm{kN} / \mathrm{mm})$ \\
\hline \multicolumn{6}{|c|}{ Values of unknown parameters used as a starting estimates } \\
\hline A & 2.5 & 6.35 & 0.16 & 0.5 & 40,000 \\
\hline B & 2.5 & 7.6 & 0.16 & 0.5 & 40,000 \\
\hline $\mathrm{C}$ & 2.5 & 11.85 & 0.65 & 0.5 & 10,000 \\
\hline \multicolumn{6}{|c|}{ Values of unknown parameters after calibration } \\
\hline A & 2.5 & 6.35 & 0.16 & 0.5 & 900,000 \\
\hline B & 2.5 & 7.6 & 0.16 & 0.5 & 648,000 \\
\hline $\mathrm{C}$ & 2.5 & 2.5 & 0.65 & 0.5 & 38,180 \\
\hline
\end{tabular}

After conducting the parameter study, following results were obtained:

COR of commonly used material for cushions usually varies between 0.5 and 0.8 . For increasing the value of $C O R$, no notable changes were recognized in the numbers of blow counts per meter.

According to the others recommendation [1-3], toe quake $-Q_{t}$, can vary from $2.5 \mathrm{~mm}$ to $D / 120$, where $D$ is pile diameter in millimeter, but skin quake $-Q_{s}$, can be taken $2.5 \mathrm{~mm}$ for all soil types. Also toe damping $J_{t}$, can be chosen $0.5 \mathrm{sec} / \mathrm{m}$ for all soil types while skin damping - $J_{s}$, is changing from $0.16 \mathrm{sec} / \mathrm{m}$ for non-cohesive soils to $0.65 \mathrm{sec} / \mathrm{m}$ for cohesive soil.

So, here only $Q_{t}$ and $J_{s}$ were considered. This study showed a slight variation of blow counts per meter, while changing these parameters.

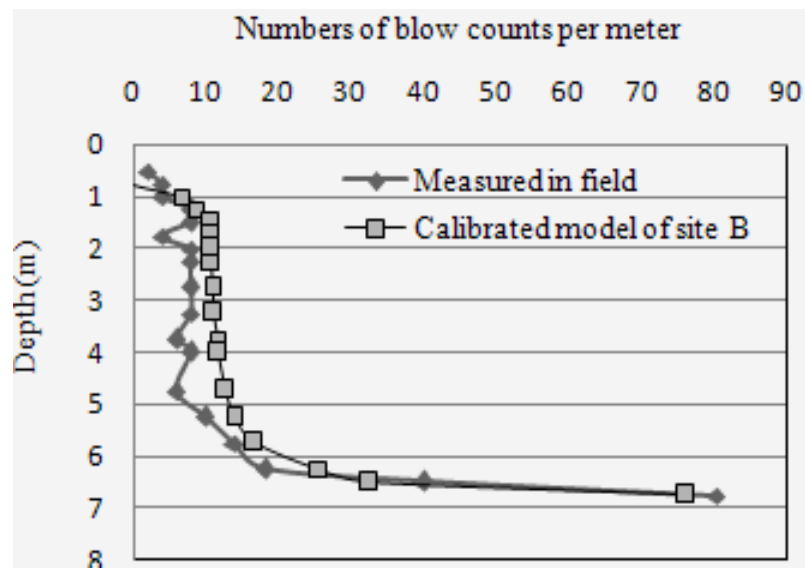

Fig. 1 Comparison of the measured blow counts per meter in field with the calibrated model of site B in GRLWEAP program.
Helmet weight was varied between 10 and $30 \mathrm{kN}$ to investigate its effect on blow counts per meter. The helmet is usually heavy and so rigid so that it is considered as a lump mass in wave equation analyses. Increasing the helmet weight whiles the hammer, pile and soil properties are constant, resulted in decreasing and then increasing of the blow counts per meter values.

The stiffness of hammer cushion $-k$, is calculated based on the $k=E . A / t$ where $E$ is elastic modulus, $A$ is cross sectional area of the cushion and $t$ is cushion thickness. To investigate the effect of hammer cushion stiffness, elastic modulus of cushion material was varied from 250 to $5,000 \mathrm{MPa}$ and the thickness was taken to $5 \mathrm{~cm}$. As it can be seen in Fig. 2, which depicts the effect of the hammer cushion stiffness in site $\mathrm{C}$, for increasing the value of the $k$ form $5,000 \mathrm{~A}$ to $100,000 \mathrm{~A}$ $\left(M N / m^{3} \times A\right)$, the blow counts per meter are decreased. It means that stiffer cushions transmit greater percentage of the hammer's energy to the pile head.

Fig. 3 shows the effect of embedded length of the pile on the number of blow counts per meter in the site A for different Delmag diesel hammers. As the pile is driven into the soil, total soil resistance at the point and skin of the pile is accumulated. According to the Fig. 3, as the embedded length of the pile is varied from 0 to $16.45 \mathrm{~m}$, blow counts per meter tend to increase exponentially. 

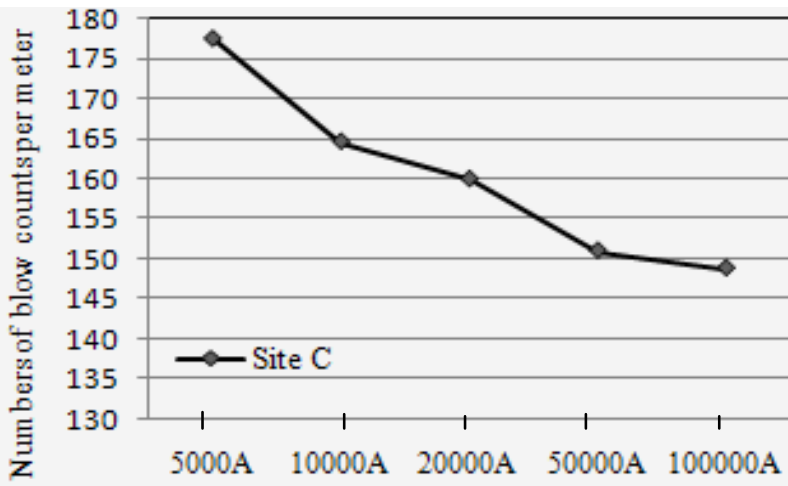

Hammer cushion stiffness $\left(M N / m^{3} \times A\right)$

Fig. 2 Effect of the hammer cushion stiffness on the blow counts per meter in site $C$.

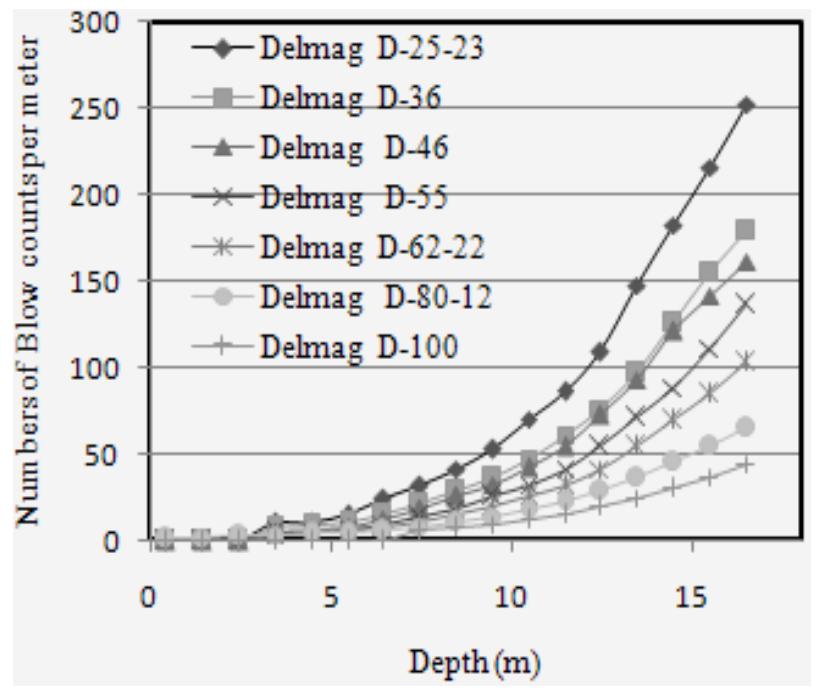

Fig. 3 Effect of embedded length of the pile on the blow counts per meter in site $A$ for various Delmag hammers.

\section{Approximate Equations}

\subsection{Approximate Equations for Hammer Selection}

In order to present an equation to determine which hammer is suitable for driving a certain pile in a known soil condition, a basic concept of energy transferring during pile driving and some of the more accurate pile driving formulas were considered. Then, using the results of parametric study, the final equations were obtained.

As the ram descending to impact the cushion, potential energy or rated energy $-E_{r}$, which is given by manufactures, is progressively converted to the kinetic energy. After losing some energy in the hammer and driving systems, the energy that actually arrives at the pile top is called transferred energy as follow:

$$
E_{t}=e_{d} \cdot e_{h} \cdot E_{r}
$$

where, $E_{t}=$ transferred energy, $E_{r}=$ rated energy, $e_{h}=$ hammer efficiency, and $e_{d}=$ loss factors in driving system. In the current study, some of the more accurate pile driving formulas like Janbu, Gate and Hiley [4-6] were considered in the terms of energy as presented in Table 4. Using the general form of Janbu formulas in the term of transferred energy and knowing the fact that energy is product of a force or resistance through a distance, leads to

$$
E_{t}=R_{u} s\left(1+\sqrt{1+\frac{C}{s}}\right)
$$

where, $E_{t}=$ transferred energy, $R_{u}=$ total soil resistance, $s=$ permanent set of the pile per blow and $C=$ elastic compression of the pile which is computed by $C=R_{u} L / A E$, where $R_{u}$ is total soil resistance, $L$ is total length of the pile, $A$ is cross sectional area of the pile and $E$ is elastic modulus of the pile.

Mean value of diesel hammer efficiency $-e_{h}$, is about 0.8 and according to the output results of GRLWEAP analyses, average quantity of loss factor in driving systems, $e_{h}$, was also obtained 0.8. Thus, for simplicity of final equation, the values of $e_{h}$ and $e_{d}$ were set to 0.8 . So, inserting corresponding values for $e_{h}$ and $e_{d}$ into the Eq. (1) and using Equations (1) and (2) give Eq. (3):

$$
E_{r}=\frac{R_{u} s}{0.64}\left(1+\sqrt{1+\frac{C}{s}}\right)
$$

Using the results of the parameter study, it was observed that number of blow counts per meter, $n$ is varying with the embedded length of the pile exponentially as presented in Fig. 3. As the set per blow, $s$ is the inverse of the $n$, the Equations (4) and (5) were obtained by plotting the embedded length of the pile with blow counts per meter for driving the pile with small and large hammers respectively as follows:

$$
s_{\min }=\frac{1}{n_{\min }}=\frac{1}{60 e^{0.07 L} e}
$$


Table 4 Pile driving formulas.

\begin{tabular}{lll}
\hline Formula & Formula based on transferred energy $\left(\mathrm{E}_{\mathrm{t}}\right)$ & Remarks \\
\hline Janbu & $\mathrm{E}_{\mathrm{t}}=\mathrm{Q}_{\mathrm{u}} \mathrm{sK}$ & $\mathrm{K}_{\mathrm{u}}=\mathrm{C}_{\mathrm{d}}\left\{1+\left(1+\lambda_{\mathrm{e}} / \mathrm{C}_{\mathrm{d}}\right)^{0.5}\right\}, \lambda_{\mathrm{e}}=\mathrm{WHL} / \mathrm{AEs}{ }^{2}$ \\
& & $\mathrm{C}_{\mathrm{d}}=0.75+0.15 \mathrm{~W}_{\mathrm{p}} / \mathrm{W}$ \\
Gate & $\mathrm{E}_{\mathrm{t}}=\left[\mathrm{Q}_{\mathrm{u}}(104.5(2.4-\log \mathrm{s}))\right]^{2}$ & $\mathrm{Q}_{\mathrm{u}}(\mathrm{kN}), \mathrm{s}(\mathrm{mm}), \mathrm{E}_{\mathrm{t}}(\mathrm{kN} \cdot \mathrm{m})$ \\
Hiley & $\mathrm{E}_{\mathrm{t}}=\left[\mathrm{Q}_{\mathrm{u}}\left(\mathrm{s}+0.5\left(\mathrm{c}_{1}+\mathrm{c}_{2}+\mathrm{c}_{3}\right)\right)\right] / \alpha^{*}$ & $\left.\alpha=\left(\mathrm{W}+\mathrm{n}^{2} \mathrm{~W}_{\mathrm{p}}\right) / \mathrm{W}+\mathrm{W}_{\mathrm{p}}\right\}$ \\
\hline
\end{tabular}

$\mathrm{c} 1, \mathrm{c} 2, \mathrm{c} 3$, and $\mathrm{n}$ are tabulated by Chellis [7]

$$
s_{\max }=\frac{1}{n_{\max }}=\frac{1}{30 e^{0.05 L} e}
$$

where, $s_{\min }=$ minimum set of pile per blow, which is usually driven by small hammers, $s_{\max }=$ maximum set of pile per blow, which is driven by large hammers, $n_{\min }$ and $n_{\max }$ are minimum and maximum number of blow counts per meter respectively, and $L_{e}=$ embedded length of the pile. Substituting Equations of (4) and (5) into the Eq. (3) yields the Equations of (6) and (7) as follow:

$$
\begin{aligned}
& E_{\min }=\frac{1}{0.64}\left(\frac{R_{u}}{60 e^{0.07 L_{e}}}\right)\left(1+\sqrt{\left.1+\frac{R_{u} L\left(60 e^{0.07 L} e\right.}{A E}\right)}\right. \\
& E_{\max }=\frac{1}{0.64}\left(\frac{R_{u}}{30 e^{0.05 L_{e}}}\right)\left(1+\sqrt{\left.1+\frac{R_{u} L\left(30 e^{0.05 L} e\right.}{A E}\right)}\right)
\end{aligned}
$$

where, $E_{\min }$ and $E_{\max }$ are minimum and maximum rated energy of diesel hammers. Ingoing parameters in Equations (6) and (7) are: total soil resistance $-R_{u}$, embedded length of the pile $-L_{e}$, total length of the pile $-L$, cross sectional area of pile $-A$ and elastic modulus of pile material $-E$. The two latter experimental equations present a range of rated energy between $E_{\min }$ and $E_{\max }$. As the rated energy of various hammers is given by manufactures, a proper hammer for a certain pile and a certain soil condition can be selected. Using Equations of (6) and (7) for condition of three studied sites showed a very good agreement with GRLWEAP output result. For instance, Table 5 indicates the output results of the proposed equations and GRLWEAP program using the data of the pile No. A1 of site A. The used hammer for driving this pile in field was Delmag D-36. According to Table 5, Eqs. (6)

Table 5 Comparison the output results of the proposed equations with GRLWEAP program.

\begin{tabular}{ll}
\hline Data of the Pile No. $A 1$ of Site A & \\
\hline Total length of the pile: & $31.45 \mathrm{~m}$ \\
Embedded length of the pile: & $16.45 \mathrm{~m}$ \\
Cross sectional area of the pile: & $420.7 \mathrm{~cm}^{2}$ \\
Total soil resistance (skin plus toe) & $3,836 \mathrm{kN}$ \\
Elastic modulus of pile: & $2 \times 10^{8} \mathrm{kN} / \mathrm{m}^{2}$ \\
Min set of pile per blow ( $\left.\mathrm{s}_{\min }\right):$ & $5.27 \times 10^{-3} \mathrm{~m}$ \\
Max set of pile per blow ( $\left.\mathrm{s}_{\max }\right):$ & $14.64 \times 10^{-3} \mathrm{~m}$ \\
\hline Output results of the proposed equations and GRLWEAP \\
\hline Min rated energy (Eq. (6)): & $115 \mathrm{~kJ}$ \\
Max rated energy (Eq. (7)): & $264 \mathrm{~kJ}$ \\
Range of hammer ID (Eqs. (6) and (7)): & $\mathrm{D}^{\mathrm{a}}-36 \mathrm{to} \mathrm{D}-80$ \\
Range of hammer ID (GRLWEAP): & D-15 to D-80 \\
Used hammer in filed: & D-36 \\
\hline D denotes Delmag diesel hammer & \\
\end{tabular}

and (7) suggest the range of Delmag D-36 to D-80 for driving of this pile.

\subsection{Approximate Equations for the Estimation of Driving Time}

The driving time can be estimated from total number of blow counts $-N$, and hammer blow rate (blows per minute) $-B$, as follow:

$$
T=\frac{N}{B}
$$

where, $T=$ total driving time, $N=$ total number of blow counts and $B=$ the blow rate. In order to obtain an experimental equation for computing total driving time, a parametric study carried out based on the GRLWEAP calibrated models, but for brevity it is not included here. Considering the pattern of blow counts per meter $-n$, with embedded length as the pile is driven into the soil usually shows an exponential growth as presented in 
Fig. 3. Thus, in this study using the general form of geometric progression formulae, $N$ is computed based on parametric study as follow:

$$
N=\frac{n_{\circ}\left(1-q^{L} e\right)}{1-q}
$$

where, $N=$ total number of blow counts, $n_{\circ}=$ blow counts in the first meter of driving, $L_{e}=$ embedded length of the pile which shows how many number of terms must be added and $q=$ common ratio which is related to the pile driving factors like the embedded length, total soil resistance and rated energy of hammer according to the parametric study results as given by

$$
\begin{aligned}
& q=\left(0.018 L_{e}+0.47\right) \times \\
& {\left[\left(34508 E_{r}^{-1.48}\right) e^{0.00053 R} u\right]^{\left(-0.11 \operatorname{Ln}\left(L_{e}\right)+0.4\right)}}
\end{aligned}
$$

where, $\mathrm{q}=$ common ratio, $L_{e}=$ embedded length, $E_{r}=$ rated energy of used hammer and $R_{u}=$ total soil resistance. According to the collected data of the sites A, B and C, averagely five blows per meter in the first meter of driving were observed. Furthermore, mean values of blow rate $-B$, in the diesel hammers in the studied sites was about 45 blows per minute. Thus, to avoid the complexity of the final equation, $n_{\circ}$ and $B$ are set to 5 and 45 respectively. Using Equations (8) and (9) with corresponding values of $n_{\circ}$ and $B$ yields

$$
T=\frac{\left(1-q{ }^{L} e\right)}{9(1-q)}
$$

where, $q-$ common ratio, must be computed from Eq. (10). It should be noted that: (1) Eq. (11) represents an estimation of total driving time which does not include interruption times (wait time). However, it shows a good agreement with GRLWEAP results; (2) If refusal occurs (blow counts goes high, e.g., greater than 300 blows per foot according to Ref. [8], the driving time calculation is meaningless.

\section{Conclusions}

The pile driving data of three different sites were collected and the driving conditions in these sites were modeled in the wave equation analysis program GRLWEAP. Unknown input parameters in GRLWEAP were obtained by calibration of the output result of this program with recoded blow counts per meter in the field. Then a parametric study was performed to produce more data. Based upon the measured and generated data, a series of equations were obtained:

(1) Equations (6) and (7) represent the minimum and maximum of rated energy. As the rated energy of various hammers is given by hammer manufactures, a proper range of hammers are achieved for driving a certain pile in a certain soil condition;

(2) Eq. (11) represents an estimation of total driving time.

It should be mentioned that obtained Equations (6), (7), and (11) do not have a general application and are valid only for the particular sites which were describe in this work.

\section{Acknowledgments}

The research was supported by Pars Geometry Consultant. Dr. A. Cheshmi was also very helpful. Their supports are acknowledged.

\section{References}

[1] PDI (Pile Dynamic, Inc.), GRLWEAP Wave Equation Analysis of Pile Driving. Procedures and Models, Cleveland, Ohio, 2003.

[2] M. Mcvay and C. Kuo, Estimate Damping and Quake by Using the Traditional Soil Testing, Report No. WPI0510838, University of Florida, Florida Department of Transportation Managment Center, USA, 1999.

[3] B. Nath, A continuum method of pile driving analysis: Comparison with the wave equation method, Computers and Geotechnics 10 (4) (1990) 265-285.

[4] R. J. Fragaszy and J. Higgins, Development of Guidelines for Constructive Control of Pile Driving and Estimation of Pile capacity, Report No: WA-RD-68.1, Washington State department of Transportation, Washington, 1985.

[5] L. Lowery, J. Finley and T. J. Hirsch, A Comparison of Dynamic Pile Driving Formulas with the Wave Equation, Research report 33-12, The Texas Transportation Institute, 
Texas A\&M University, The Texas Highway Department, Texas, 1968.

[6] T. Allen, Development of the WSDOT Pile Driving Formula and Its Calibration for Load and Resistance Factor Design, Report No: WA-RD-610.1, HQ Material labartobary, Geotechnical Division, Washington State Department of Transportation, Olympia, Washington, 2005.
[7] R. Chellis, Pile Foundations, 2nd ed., McGraw-Hill, New York, 1961.

[8] API (American Petroleum Institute), Recommended Practice Planning, Designing, and Construction Fixed Offshore Platform Working Stress Design (21th ed.), API Recommended practice 2A-WSD (RP 2A-WSD), 2000. 